http://dx.doi.org/10.11646/zootaxa.3652.1.5

http://zoobank.org/urn:lsid:zoobank.org:pub:416B25B6-D885-4DAD-94C7-13AEBD98115E

\title{
Three new species of Neozygina Dietrich \& Dmitriev (Hemiptera, Cicadellidae, Typhlocybinae) from Argentina, with a key to South American species
}

\author{
MARÍA INÉS CATALANO ${ }^{1,4}$, SUSANA PARADELL ${ }^{2} \&$ CHRISTOPHER H. DIETRICH $^{3}$ \\ ${ }^{1}$ Centro de Bioinvestigaciones, Universidad Nacional del Noroeste de la Provincia de Buenos Aires, Monteagudo 2772, Pergamino, \\ Buenos Aires, 2700, Argentina. CONICET \\ ${ }^{2}$ División Entomología, Facultad de Ciencias Naturales y Museo, Universidad Nacional de La Plata. Paseo del Bosque s/n, La Plata, \\ Buenos Aires, 1900, Argentina. CIC. \\ ${ }^{3}$ Illinois Natural History Survey, Institute of Natural Resource Sustainability, University of Illinois, 1816 S. Oak Street, Champaign, \\ Illinois, 61820, USA \\ ${ }^{4}$ Corresponding author.E-mails: mariainescatalano@unnoba.edu.ar; mariainescatalano@gmail.com
}

\begin{abstract}
Three new species of Neozygina Dietrich \& Dmitriev are described from Argentina, N. apicalis sp. nov., N. bifurcata sp. nov. and $N$. spinula sp. nov. Detailed morphological descriptions and illustrations of the new species are provided, and a key to South American species of the genus is given.
\end{abstract}

Key words: Auchenorrhyncha, identification, morphology, distribution

\section{Introduction}

The genus Neozygina includes 25 previously described species distributed from the western United States to Argentina (Dietrich \& Dmitriev 2007) and is the most diverse genus of the tribe Erythroneurini recorded in South America. Species of Neozygina differ from other New World Erythroneurini in having both dorsal and ventral appendages present on the male pygofer, one or more macrosetae just basad of the dorsal appendage on the pygofer margin, and a pair of conspicuous black spots on the crown (Dietrich \& Dmitriev 2007). Phylogenetic analysis of morphological data recovered Neozygina as the monophyletic sister group to a clade comprising the New World genera Mexigina, Hepzygina, and Zyginama (Dietrich \& Dmitriev 2006). The few available host records indicate that species of the genus feed on shrubs or herbaceous vegetation, including grasses (Dietrich \& Dmitriev 2007). In Argentina, the genus Neozygina is represented by three species (N. argentiniensis Dietrich \& Dmitriev 2007, $N$ expanda Dietrich \& Dmitriev 2007, and N. forcipata Dietrich \& Dmitriev 2007). In the current work, three new species of Neozygina Dietrich \& Dmitriev are described and illustrated from Argentina, and a key including the new species is given.

\section{Materials and methods}

The specimens were collected with Malaise and mercury vapor lights traps in Chaco, Jujuy, and Tucumán provinces. For morphological study of the genital structures, clearing was accomplished by immersion of the entire abdomen in a solution of $10 \% \mathrm{KOH}$ at room temperature for several hours followed by several rinses with water. For illustration, genital structures were embedded in glycerin. The color pattern here described is the post-mortem coloration. In living or recently collected individuals the coloration can be more vivid relative to that of old preserved specimens. Morphological terminology follows Young (1952) and Dietrich (2005) for habitus and genitalia characters. Digital photographs were taken using a QImaging Micropublisher 3.3 digital camera mounted on an Olympus SZX12 stereomicroscope. The type-series of the new species are deposited in the entomological 
collection of Museo de Ciencias Naturales de La Plata, Argentina (MLP), Illinois Natural History Survey, USA (INHS) and Instituto Miguel Lillo, Tucumán, Argentina (IML).

\section{Taxonomy}

\section{Erythroneurini Young}

\section{Neozygina Dietrich \& Dmitriev 2006}

Neozygina Dietrich \& Dmitriev, 2006: 147-148. Type species: Erythroneura ceonothana Beamer, 1934: 287, designated by Dietrich \& Dmitriev, 2006.

Diagnosis. Crown with pair of large brown or black preapical spots; forewing lacking distinct spots or oblique patterns, inner apical cell with base oblique. Male pygofer with dorsal appendage well development, one or more macrosetae present basad of dorsal appendage, ventral appendage present. Style apex truncate, footlike, with only two points, preapical lobe well developed. Connective U or Y-shaped. Aedeagus with dorsal apodeme well developed, usually T-shaped in posterior view, shaft often with paired or unpaired basal or distal process, or both; unpaired basal process, when present, closely appressed to shaft.

Biology. Species of the genus feed on shrubs, grasses or herbaceous vegetation.

Distribution. Western United States to Argentina.

\section{Key to males of South American Neozygina (modified from Dietrich and Dmitriev 2007 to include the new species)}

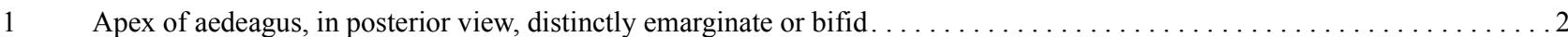

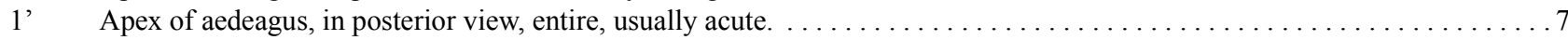

2 Aedeagus with pair of processes arising near base or in the middle of shaft and extended posterodorsad $\ldots \ldots \ldots \ldots . . .3$

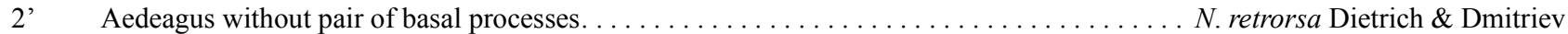

3 Aedeagus with pair of processes arising near base of shaft, shaft tubular, slender; distal process arising ventral to gonopore ..

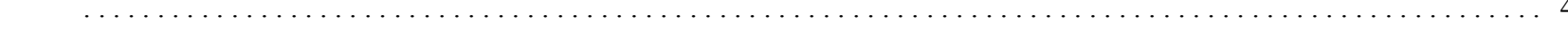

3' Aedeagus with pair of processes arising near midlength of shaft, shaft compressed; distal process arising dorsal to gonopore

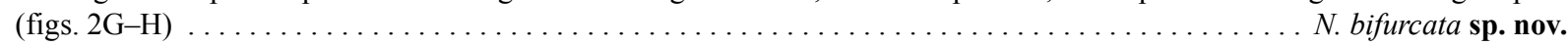

4 Apex of aedeagus, in posterior view, deeply emarginate, forcipate, distal processes curved toward midline . . . . . . . 5 5

4. Apex of aedeagus, in posterior view, deeply emarginate, not forcipate, distal processes curved away from midline ........

$\ldots \ldots \ldots \ldots \ldots \ldots \ldots \ldots \ldots \ldots \ldots \ldots \ldots \ldots \ldots \ldots \ldots \ldots \ldots \ldots \ldots \ldots \ldots \ldots \ldots \ldots \ldots \ldots \ldots \ldots \ldots$. argentiniensis Dietrich \& Dmitriev

4" Apex of aedeagus, in posterior view, weakly emarginate, with asymmetrical subapical spine arising on anterior surface

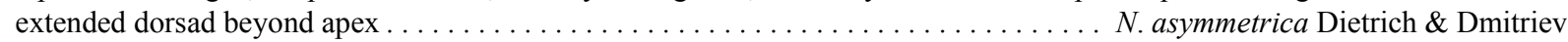

5 Apex of aedeagus, in posterior view, more than twice as wide preapically than at level of gonopore

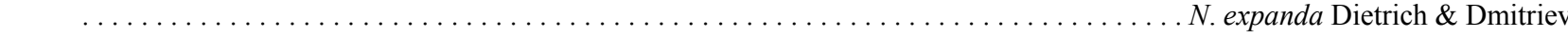

5, Apex of aedeagus, in posterior view, only slightly wider preapically than at level of gonopore $\ldots \ldots \ldots \ldots \ldots \ldots$

6 Apex of aedeagus, in posterior view, with pair of lateral preapical spines; pygofer lobe with two macrosetae (figs. 3G-H, C) . Apex of aedeagus, in posterior view, without a pair of lateral preapical spines; pygofer with a single macroseta $\ldots . \ldots \ldots$

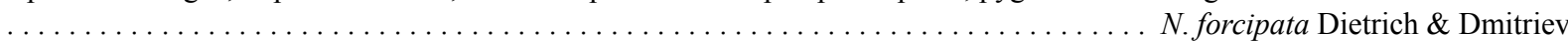
Aedeagus with two pairs of apical processes, one short and extended anteroventrad, other long and extended posteroventrad; preapical processes arising from shaft $($ figs. $1 \mathrm{G}-\mathrm{H}) \ldots \ldots \ldots \ldots \ldots \ldots \ldots \ldots \ldots \ldots \ldots \ldots \ldots \ldots \ldots$ apicalis sp. nov.

7. Aedeagus with one pair of apical processes extended ventrolaterad; preapical processes arising from single stem extended posterad from shaft $\ldots \ldots \ldots \ldots \ldots \ldots \ldots \ldots \ldots \ldots \ldots \ldots \ldots \ldots \ldots \ldots \ldots \ldots \ldots \ldots \ldots \ldots \ldots \ldots \ldots$ abancaysis Dietrich \& Dmitriev

\section{Neozygina apicalis sp. nov.}

(Figs. 1A-H)

Description. Length of male $2.9 \mathrm{~mm}$. Ground color stramineous, infused with light brown; mesonotum with basal triangles dark brown; forewing without distinct markings (fig. 1A). 

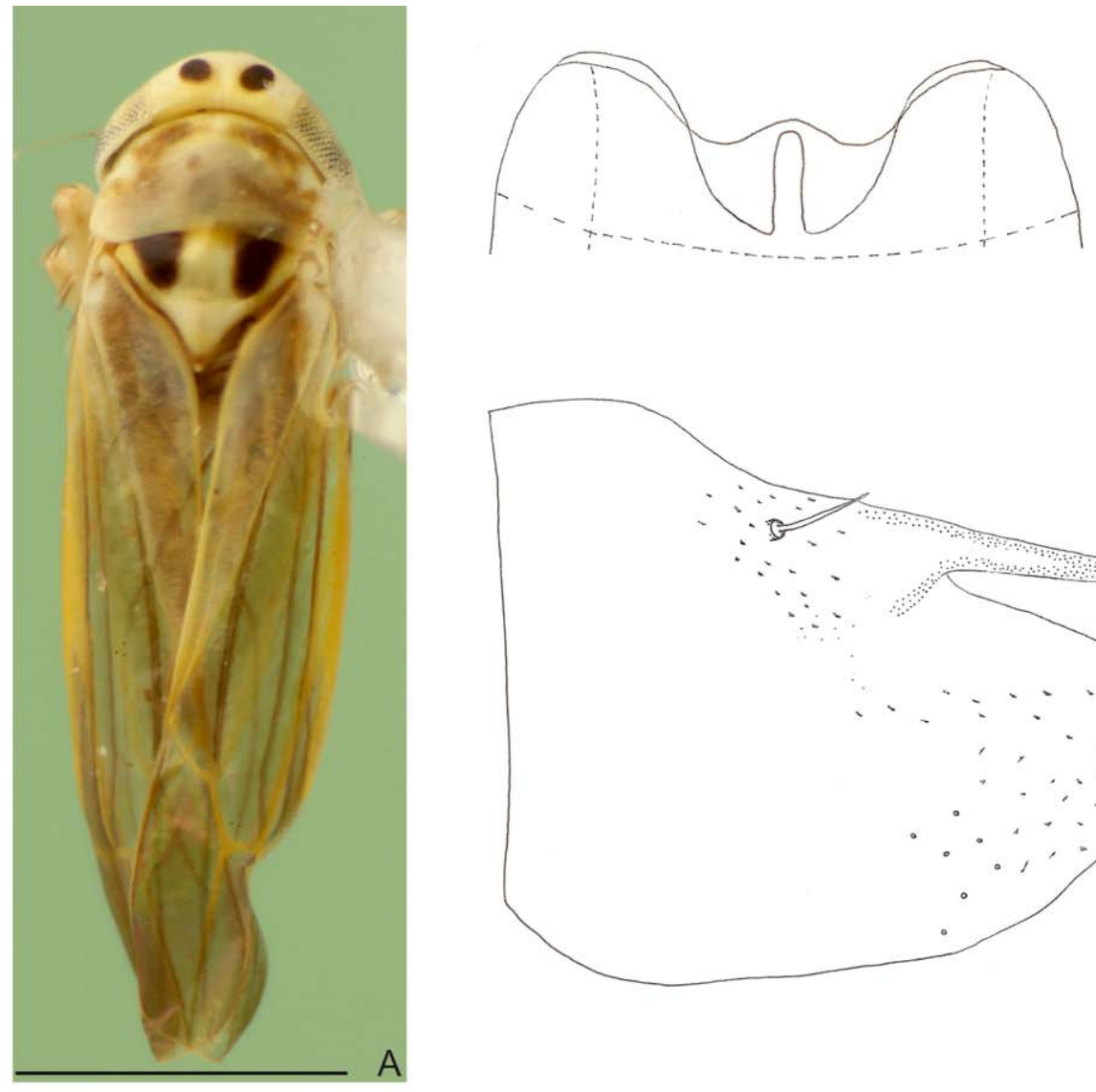

B
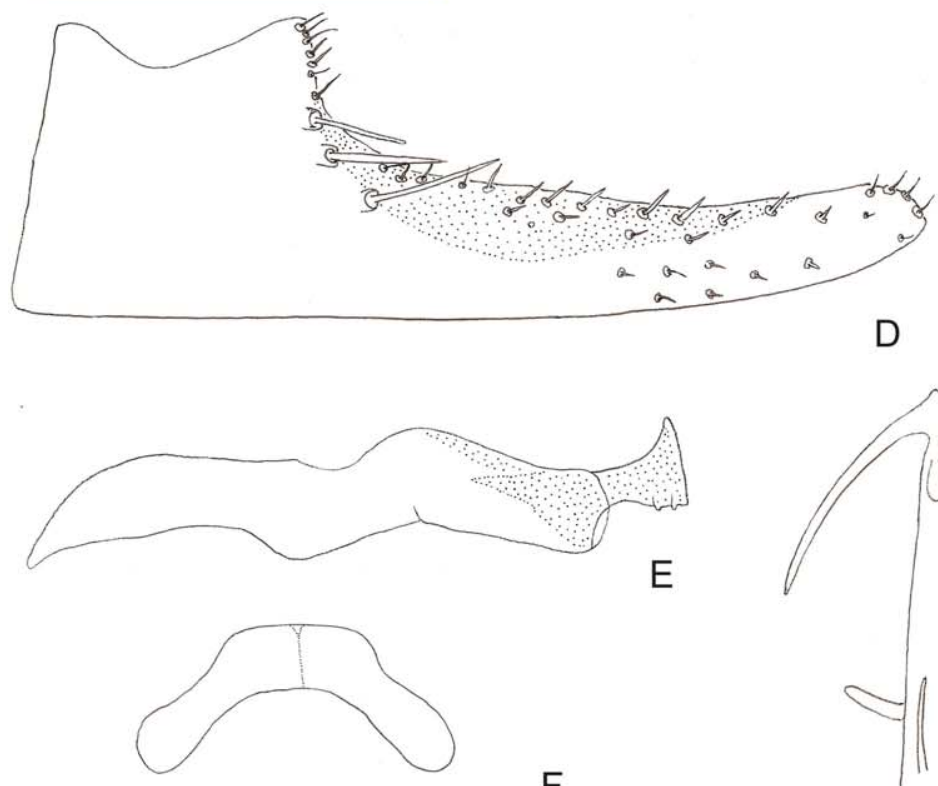

$E$

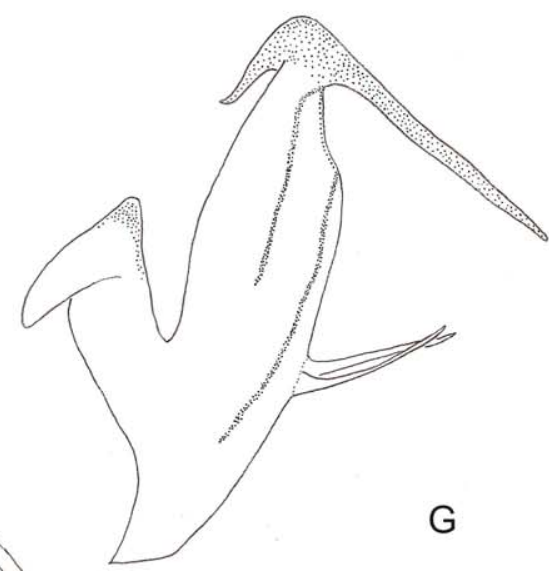

$\mathrm{F}$

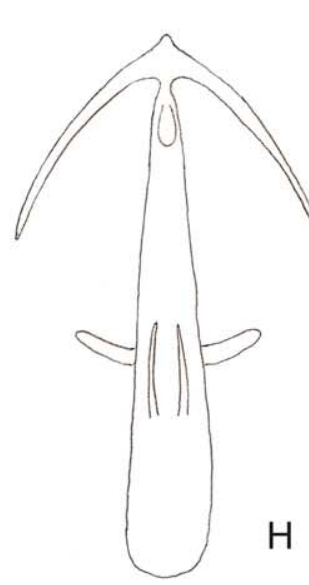

FIGURE 1. Neozygina apicalis sp. nov. A, male, dorsal habitus; B, second sternal apodemes; C, pygofer, lateral view; D, subgenital plate; E, style; F, connective; G, aedeagus in lateral view; H, aedeagus in posterior view. Scale $=0.1 \mathrm{~mm}$.

Male: Second sternal apodemes (2S) (fig. 1B) not reaching posterior margin of third segment. Pygofer (fig. 1C) with conspicuous microsetae, single macroseta near base of dorsal appendage; dorsal appendage arising near base of lobe, straight in lateral view, curved mesad in dorsal view, extended nearly to apex of pygofer; ventral 
appendage arising preapically, well developed, extended dorsomesad. Subgenital plate (fig. 1D) with basolateral angle acute; submarginal row of three macrosetae; marginal row of microsetae from subbasal angle to apex. Style (fig. 1E) with preapical lobe rounded, enlarged; apex truncate with lateral angle short, acute, medial angle $\sim 90^{\circ}$, with small preapical denticuli. Connective (fig. 1F) broadly U-shaped. Aedeagus (figs. 1G-H) with preatrium absent, dorsal apodeme T-shaped in posterior view; shaft slightly compressed, paired subbasal ventral processes less than half length of shaft, close to each other throughout length, divergent from shaft in lateral view; paired distal processes arising slightly distad of gonopore, long, slender, extended ventrolaterad; pair of short apical dorsal processes directed anteroventrad; apex in posterior view slender, not bifurcate; gonopore subapical.

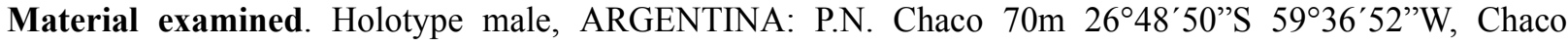
province, 11-13 January 2008 (Dietrich et al col. Malaise trap) [MLP]. Paratypes: 1 male and 1 female, same data as holotype [INHS]; 2 males: ARGENTINA: Las Tipas 966 m 263'53.16”S 65²3'03.28”W, Tucumán province, 16 November- 4 December 2011 (Virla col. Malaise trap) [1 male in MLP; 1 male in IML].

Etymology. The specific name refers to the position of the aedeagal processes apical to gonopore.

Note. This species closely resembles $N$. argentiniensis but has the dorsal appendage of the pygofer shorter, and two pairs of apical processes arising slightly distad of the gonopore.

\section{Neozygina bifurcata sp. nov.}

(Figs. 2A-H)

Description. Length of male 2.8-3.0 mm. Ground color stramineous, infused with brown; anteclypeus, lateral margin of frontoclypeus and mesonotal triangles brown; forewing brown, veins pale, brochosome field yellowish (fig. 2A).

Male: Second sternal apodemes (2S) (fig. 2B) reaching fourth segment. Pygofer (fig. 2C) with conspicuous microsetae, two macrosetae near base of dorsal appendage; dorsal appendage arising near base of lobe, straight in lateral and dorsal view, not reaching apex of lobe; ventral appendage arising preapically, well developed, extended dorsomesad, sinuate, apex extended mesad in dorsal view. Subgenital plate (fig. 2D) with basolateral angle obtuse; with submarginal row of three macrosetae; marginal row of microsetae from subbasal angle to apex. Style (fig. 2E) with preapical lobe quadrangular, enlarged; apex truncate with lateral angle short, acute, medial angle $90^{\circ}$, without preapical denticuli. Connective (fig. 2F) Y-shaped with stem and arms short. Aedeagus (figs. 2G-H) with short preatrium, dorsal apodeme T-shaped in posterior view; shaft compressed, paired subbasal ventral processes less than half length of shaft, parallel to each other throughout length, divergent from shaft in lateral view; paired distal processes arising dorsad of gonopore, long, slender, extended ventrolaterad with bifurcate apices; apex in posterior view bifid, forming pair of short, rounded apical dorsal processes; gonopore subapical.

Material examined. Holotype male, ARGENTINA: P.N. Chaco, Laguna Yacaré 60m 26⒋ $47^{\prime} 50^{\prime \prime S}$ 59 36'49”'W, Chaco province, 10-13 January 2008 (Dietrich et al col. Malaise trap) [MLP]. Paratype: 1 male, same data as holotype [INHS].

Etymology. The specific name refers to the shape of the distal aedeagal processes.

Note. This species closely resembles $N$. antlera but has the aedeagus with basal processes, and the apex bifid (typical of South American species).

\section{Neozygina spinula sp. nov.}

(Figs. 3A-H)

Description. Length of male $2.7-2.8 \mathrm{~mm}$. Ground color stramineous, infused with brown; dorsum mostly brown, anteclypeus, lateral margin of frontoclypeus and mesonotal triangles dark brown; forewing brown, veins and brocosome field yellow-orangish (fig. 3A).

Male: Second sternal apodemes (2S) (fig. 3B) slightly reaching fourth segment. Pygofer (fig. 3C) with conspicuous microsetae, one macroseta near base of dorsal appendage and other between dorsal and ventral appendage; dorsal appendage arising near base of lobe, slightly curved ventrad in lateral view and straight in dorsal view, not reaching apex of lobe; ventral appendage arising preapically, well developed, extended dorsomesad. Subgenital plate (fig. 3D) with basolateral angle acute; with submarginal row of three macrosetae; marginal row of 
microsetae from subbasal angle to apex. Style (fig. 3E) with preapical lobe rounded, enlarged; apex truncate with lateral angle short, acute, medial angle $90^{\circ}$. Connective (fig. 3F) Y-shaped with stem and arms short. Aedeagus (figs. 3G-H) with preatrium absent, dorsal apodeme T-shaped in posterior view; shaft tubular, in lateral view slender; paired subbasal ventral processes approximately half length of shaft, slightly divergent from each other, divergent from shaft in lateral view; paired distal processes arising ventrad of gonopore, long, slender, extended ventrolaterad; apex in posterior view bifid, forming pair of forcipate apical dorsal processes with short lateral spine near midlength of each process; gonopore apical.
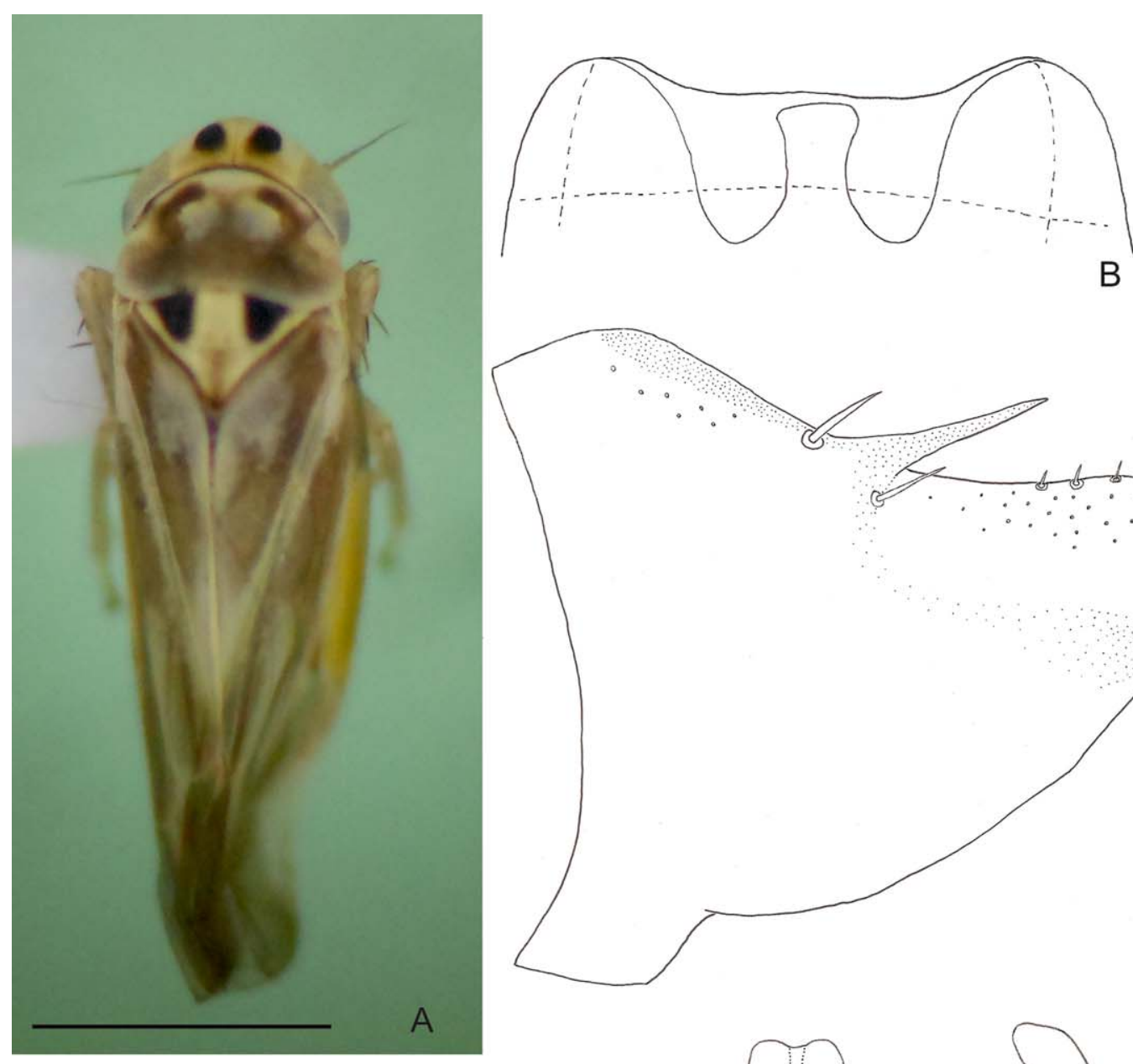

B
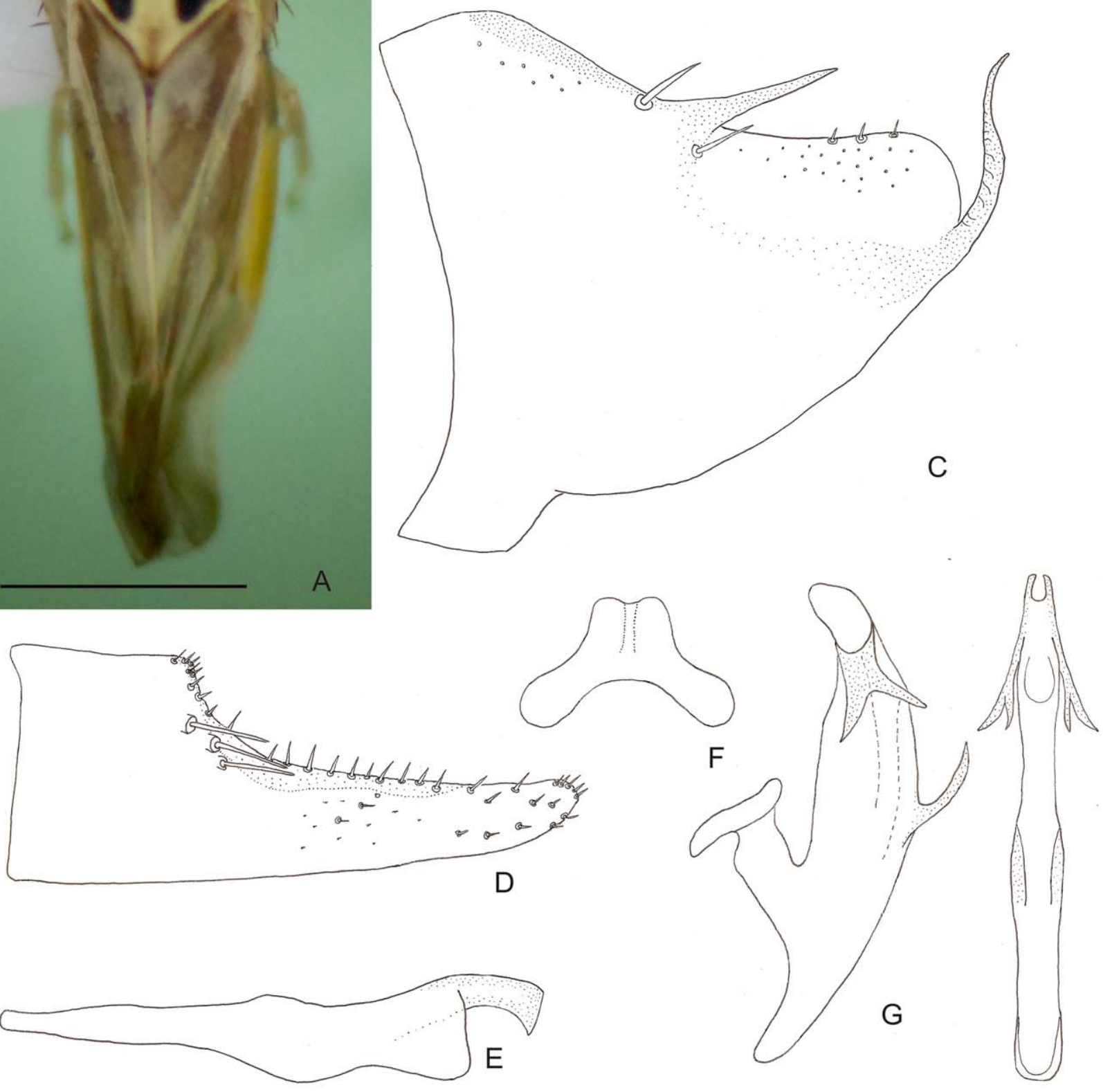

D

FIGURE 2. Neozygina bifurcata sp. nov. A, male, dorsal habitus; B, second sternal apodemes; C, pygofer, lateral view; D, subgenital plate; E, style; F, connective; G, aedeagus in lateral view; H, aedeagus in posterior view. Scale $=0.1 \mathrm{~mm}$. 

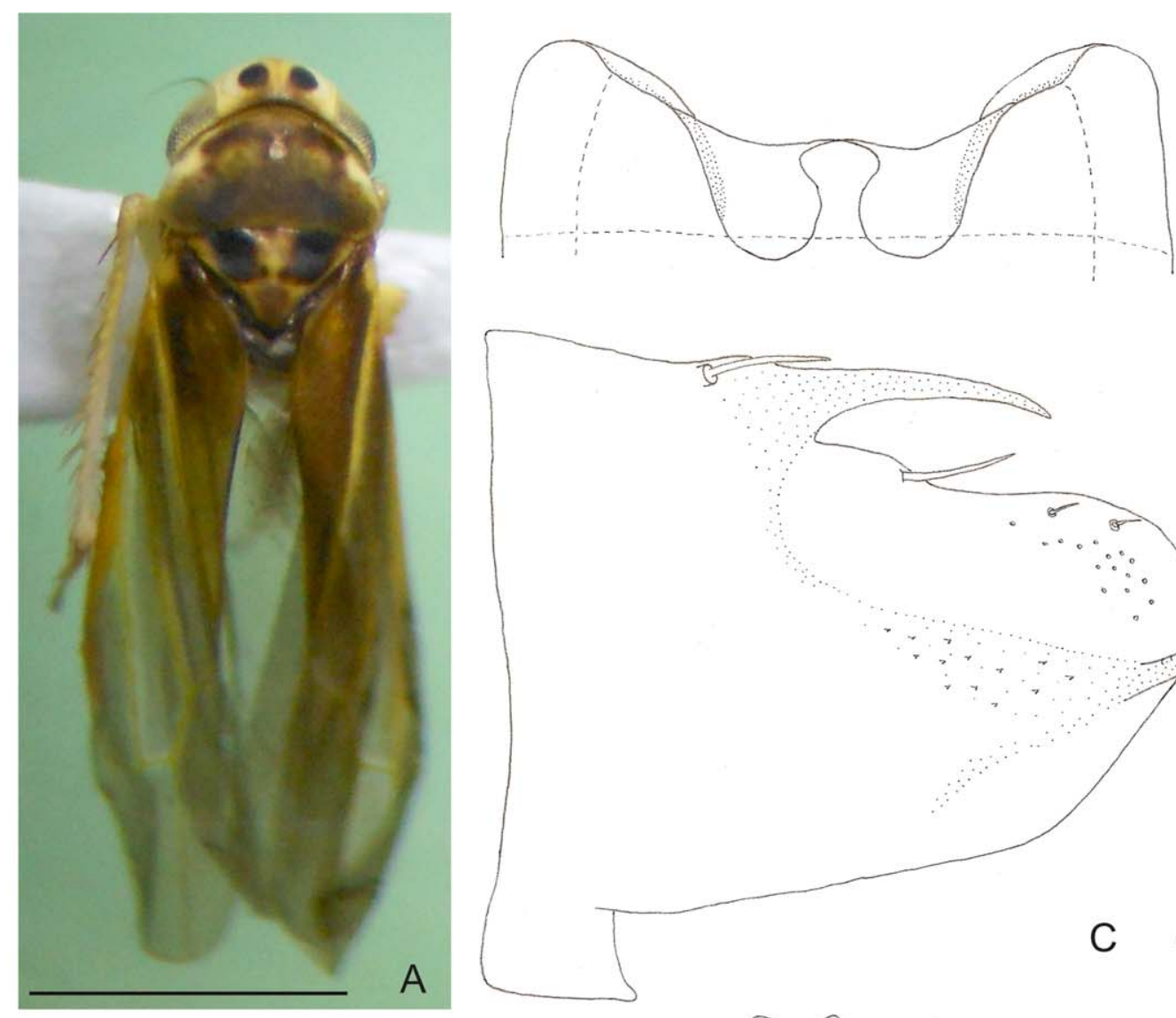

B

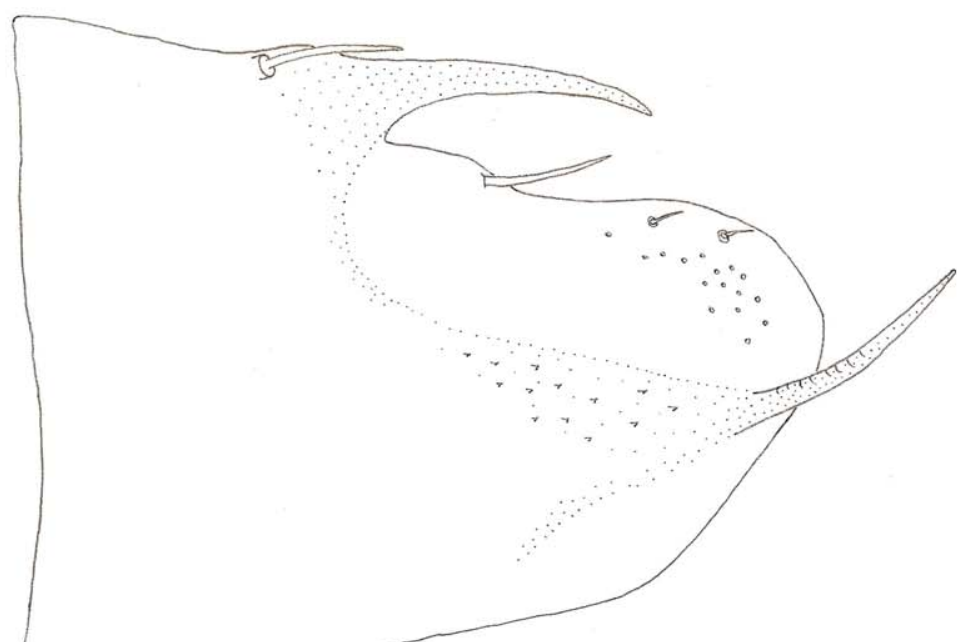

A
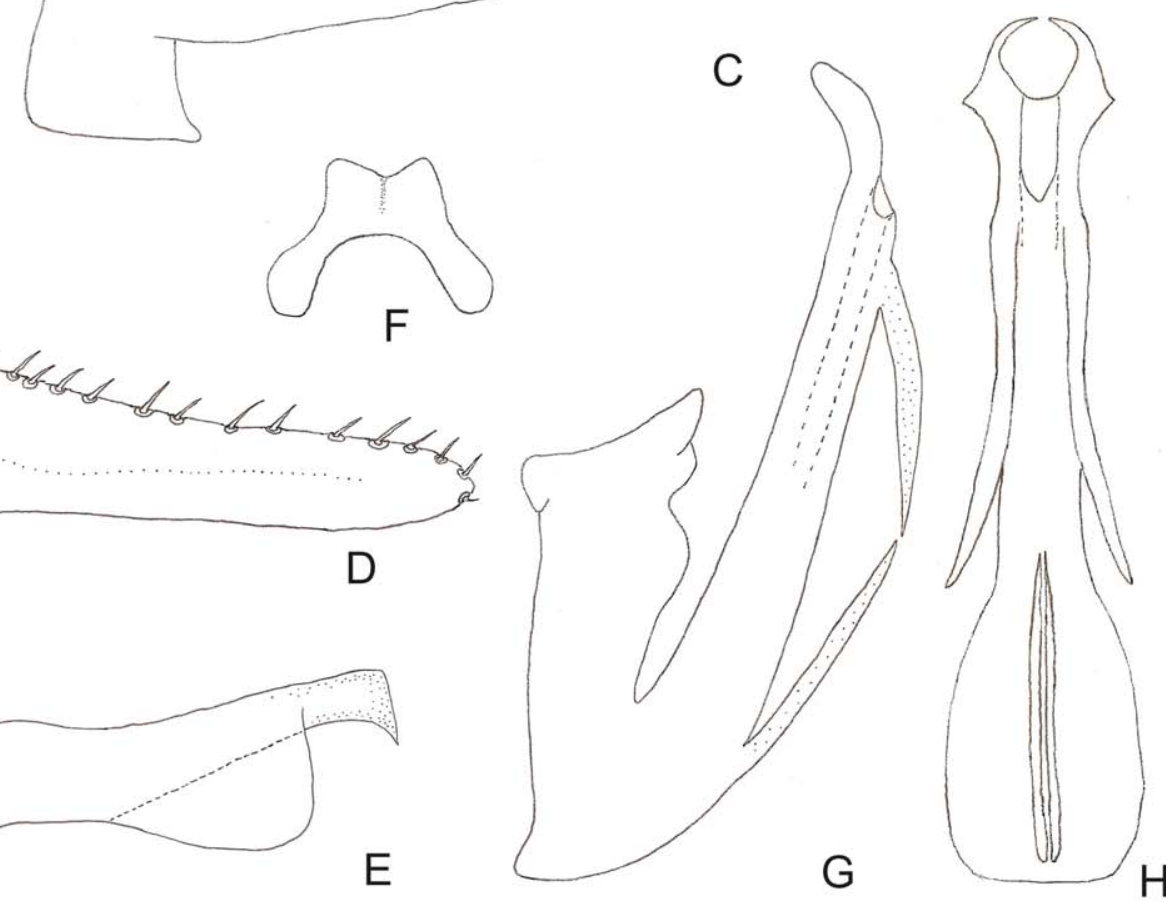

$E$

G

FIGURE 3. Neozygina spinula sp. nov. A, male, dorsal habitus; B, second sternal apodemes; C, pygofer, lateral view; D, subgenital plate; E, style; F, connective; G, aedeagus in lateral view; H, aedeagus in posterior view. Scale $=0.1 \mathrm{~mm}$.

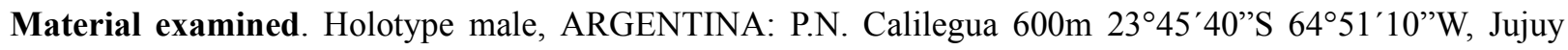
province, 15 January 2008 (Dietrich col. Hg. vapor lights) [MLP]. Paratype: 1 male, same data as holotype [INHS].

Etymology. The specific name refers to the lateral spines of the distal aedeagal appendages.

Note. This species closely resembles $N$. forcipata but has a macrosetae between both pygofer processes and the dorsal pygofer appendage with a lateral spine, and lacks small teeth near the base of the dorsal margin of the aedeagus. 


\section{New records}

Neozygina argentiniensis Dietrich and Dmitriev 2007

Distribution: Catamarca, Argentina.

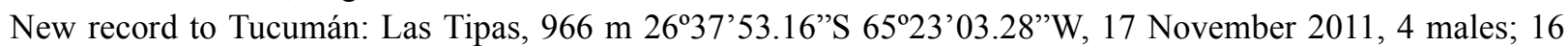
December 2011, 3 males (Virla col. Malaise trap) [MLP; IML].

\section{Neozygina forcipata Dietrich and Dmitriev 2007}

Distribution: La Rioja, Argentina.

New record to Tucumán: Las Tipas, 966 m 26037'53.16”S 65²3’03.28”W, 3 November 2011, 2 males; 3 January 2012, 5 males (Virla col. Malaise trap) [MLP; IML].

\section{Acknowledgements}

We would like to express our sincere gratitude to Dr. Eduardo Virla for his kindness in sending us the material from Tucumán province he collected for identification. We also thank María Marta Cigliano and Santiago Plischuk for facilitating field work by CHD in Argentina that led to the collection of other specimens included in this study. This research was supported in part by U.S. National Science Foundation grants DEB 0529679 and 0715499 (to CHD), CONICET and CIC (Argentina).

\section{References}

Dietrich, C. (2005) Keys to the families of Cicadomorpha and subfamilies and tribes of Cicadellidae (Hemiptera: Auchenorrhyncha). Florida Entomologist, 88, 502-517.

Dietrich, C. \& Dmitriev, D. (2006) Review of the New World genera of the leafhopper tribe Erythroneurini (Hemiptera: Cicadellidae: Typhlocybinae). Bulletin of the Illinois Natural History Survey, 37, 117-190.

Dietrich, C. \& Dmitriev, D. (2007) Revision of the New World leafhopper genus Neozygina Dietrich and Dmitriev (Hemiptera: Cicadellidae: Typhlocybinae: Erythroneurini). Zootaxa, 1475, 27-42.

Young, D. (1952) A reclassification of western Hemisphere Typhlocybinae (Homoptera, Cicadellidae). Kansas University Science Bulletin, 35, 1-217. 